\title{
Study of unmachined area in intricate machining after rough cut in WEDM
}

\author{
Kamal Jangra*
}

Department of Mechanical Engineering, YMCA University of Science and Technology, Faridabad, India

\begin{tabular}{|c|c|}
\hline$\overline{A \text { A R I C LE I NFO }}$ & A B S TRACT \\
\hline $\begin{array}{l}\text { Article history: } \\
\text { Received 10 January } 2012 \\
\text { Accepted May } 242012 \\
\text { Available online } \\
25 \text { May } 2012 \\
\text { Keywords: } \\
\text { Wire electrical discharge } \\
\text { machining } \\
\text { Unmachined surface area } \\
\text { Trim cut }\end{array}$ & $\begin{array}{l}\text { Wire electrical discharge machining (WEDM) is well known process for generating intricate and } \\
\text { complex profiles in hard metal matrix composites. But damaged surface layer with poor surface } \\
\text { integrity is a major disadvantage of WEDM. Beside poor damaged surface layer, after rough/first } \\
\text { cut in WEDM, some surface area remains unmachined on work surface during intricate } \\
\text { machining such as in die cutting. This paper presents a study on unmachined surface area named } \\
\text { as surface projection, in die cutting after rough cut in WEDM. Using scanning electron } \\
\text { microscope images, length of unmachined surface projections have been determined. In order to } \\
\text { minimize these surface projections from small cavities having complex geometries, trim cutting } \\
\text { operation is the best alternative. Results show that using more than one trim cut with appropriate } \\
\text { wire offset value, surface projections can be minimized, successfully. }\end{array}$ \\
\hline
\end{tabular}

\section{Introduction}

Wire electrical discharge machining (WEDM) is a special form of electrical discharge machining (EDM) which is now used conventionally in manufacturing industries for generating intricate and complex profiles in hard metal alloys and metal matrix composites, with high degree of accuracy, without making any mechanical contact (Jangra et al., 2010). Application of WEDM has grown from simple making of tools and dies to the best alternative of producing micro-scale parts with the highest degree of dimensional accuracy and surface finish in various fields of engineering including automotive, aerospace, medical, optical, dental, jewellery industries, etc. (Ho et al., 2004). In WEDM, surface material is eroded by melting or evaporation due to large amount of heat generated between the work material and downward moving wire electrode as shown in Fig. 1.

Although, WEDM can machine hard composite material with more accuracy and precision, some unwanted surface flaws such as recast layer, heat affected zone, etc. have also been observed on machined surface. Since the melting and evaporation of material in WEDM is due to high heat energy, some part of this heat is transferred to the work material which develops the heat affected zone on work surface. The heat affected zone has different surface morphology as compared to base material. It consists of recast layer or white layer having hollow cavities and several micro-cracks due to thermal residual stresses (Lee \& Li, 2003; Wang et al., 2009). Recast layer is a hard skin on the work surface

* Corresponding author. Tel: 91-9416358678

E-mail: kamaljangra84@gmail.com (K. Jangra)

(C) 2012 Growing Science Ltd. All rights reserved. doi: $10.5267 /$ j.ijiec.2012.05.003 
formed due to the re-solidification of melted residual material which was not completely expelled during the process (Puri \& Bhattacharyya, 2005).

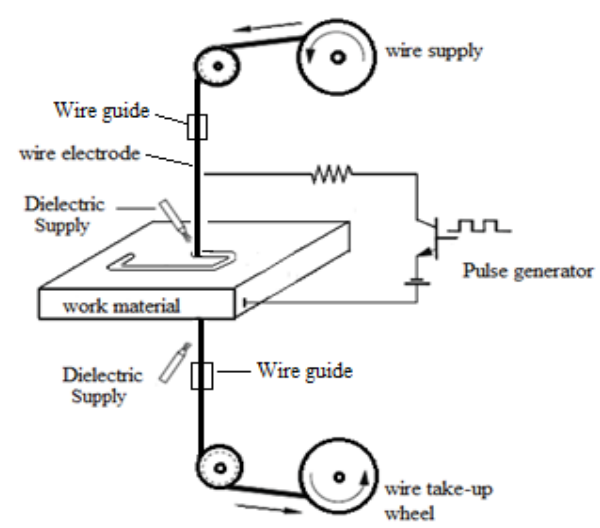

Fig. 1. Representation of WEDM process

In case of die manufacturing with WEDM, avoiding the surface degradation is the main concern to improve the die life. Therefore, one or more trim cuts (Sarkar et al., 2005, 2008) are required after rough cut, to minimize the surface defects and geometrical inaccuracies. But sometimes, improper parameters setting during rough cutting operation may deteriorate the work surface very severely, which may not be improved considerably after one or more trim cuts (Juhr et al., 2004). Several studies have been conducted on EDM/WEDM to analyse the surface characteristics of the eroded work surfaces (Kruth et al., 1995; Kahng \& Rajurkar, 1997; Rebelo et al., 1998; Lee \& Li, 2003; Boujelbene et al., 2009; Veldhuis et al., 2010). All these studies explored the effect of process parameters on depth of recast layer and heat affected zone. But in case of intricate machining on WEDM such as in die cutting, some surface area remains unmachined after rough cutting operation, which has not been investigated so far. This unmachined area named as surface projection, if not eliminated from die surface, may affect severely the die performance and quality of the final components. Therefore, the aim of this paper is to present some investigations on surface projections appeared after rough cutting operation in intricate machining on WEDM.

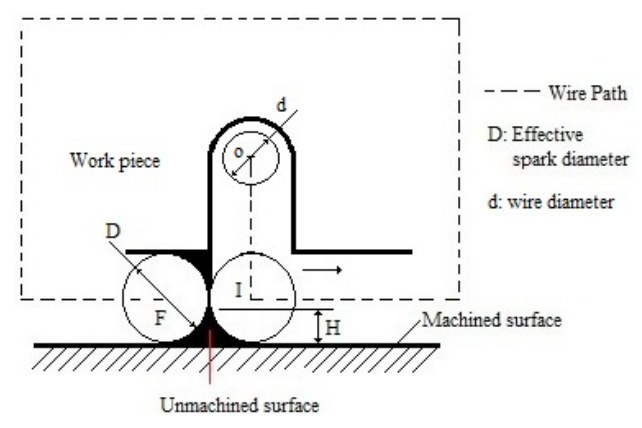

Fig. 2. Unmachined area on work surface after rough cut in WEDM

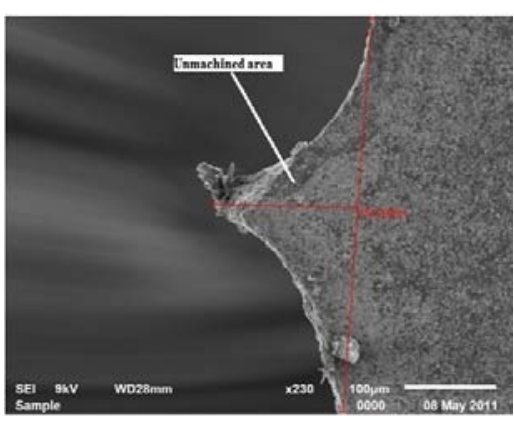

Fig. 3. Surface projection on die cavity

\section{Unmachined Area/Surface Projection}

In intricate machining of work materials on WEDM such as in die cutting, some surface area remains unmachined after first/rough cut as shown in Fig. 2. In Fig. 2, the dotted line (OIF) shows the wire path starting form point $\mathrm{O}$. D is the effective spark diameter which is the sum of wire electrode diameters (d) and spark gap (SG). Spark gap is the gap between wire periphery and work surface which is occupied by the large number of negatively and positively charged ions which causes the heat generation at two electrodes. According to the path programme, wire electrode should reach the point I to cut out the inside material (punch) for cavity formation. But in actual practice, cutting takes place earlier at point $\mathrm{F}$ and no spark takes place further. As a result, some area or projection left unmachined on work surface. 
A triangular like shape appears for these surface projections as shown in Fig. 3. The length $(\mathrm{H})$ of surface projection depends on effective spark diameter which is function of discharge energy across the electrodes.

\section{Experimental procedure}

A 5-axis sprint cut (epulse-40) WEDM, manufactured by Electronica Machine Tool Ltd India, was used as a machine tool for experimentation. Distilled water was used as a dielectric fluid with conductivity 20S. Zinc coated brass wire of diameter $0.25 \mathrm{~mm}$ was used as an electrode because of its good capability to sustain high discharge energy. In present machine tool, parameters can be varied under following range: discharge current (Ip), 10-230amp; pulse-on time (Ton), 101-131 $\mu$ s; pulse-off time (Toff), 10-63 $\mu$ s; servo voltage (SV), 0-90V; dielectric flow rate (DFR), 0-12 litre per minute $\left(\mathrm{LM}^{-1}\right)$; wire feed rate (WF), 1-15m/min; wire tension (WT), 1-15N. Tungsten carbide (WC-Co) composite having $5.3 \% \mathrm{Co}$ was used as a work material in the form of rectangular plate of $13 \mathrm{~mm}$ thickness. The density and hardness of WC-5.3\%Co composite was measured as $14.95 \mathrm{~g} / \mathrm{cm}^{3}$ and 77 HRC respectively. Die cavities of pentagon shape having side $6 \mathrm{~mm}$ were produced in WC-Co composite plate. For this purpose, fine holes of diameter $1 \mathrm{~mm}$ were drilled on carbide plate at preselected points using EDM for passing the wire electrode as shown in Fig. 4.

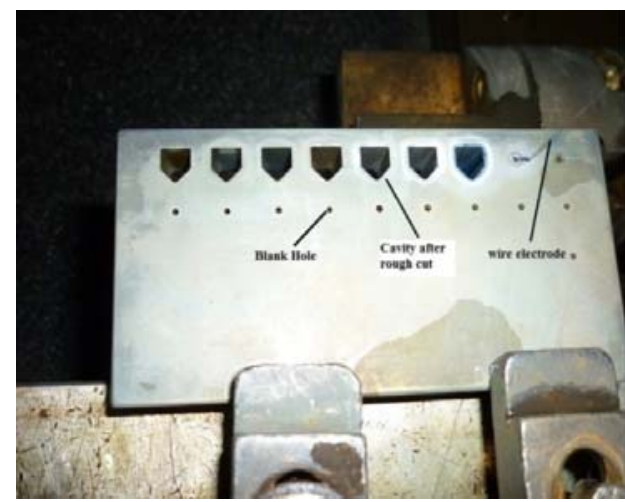

Fig. 4. Intricate machining in carbide plate

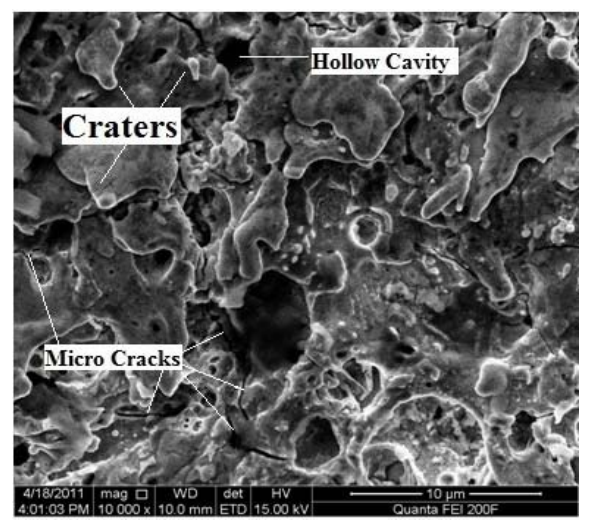

Fig. 5. SEM image of WEDMed surface

After intricate machining, following procedure was followed to examine the unmachined area on die cavity:

(i) Using WEDM, one side of the each die cavity was cut out in a length of $4 \mathrm{~mm}$ which must include the machining area between point $\mathrm{F}$ and I (Fig. 2).

(ii) Transverse sections were etched and grinded mechanically using standard procedure for observation on scanning electron microscope (SEM).

(iii) Using SEM, length $(\mathrm{H})$ of unmachined area or surface projection was determined for each specimen as shown in Fig. 3.

\section{Results and Discussions}

In WEDM, intense heat is generated between the wire electrode and work surface causing the localised melting or evaporation of the workpiece material. Due to the continuous dielectric flushing, rapid cooling takes place after melting the work material which results in high thermal stresses (Lee \& Li, 2003) on work surface causing large size craters, micro-cracks and hollow cavities on machined surface as shown in Fig. 5. But the main focus of present study is on surface projections. Therefore, SEM images were taken for transverse section of die cavities. The shape and length $(\mathrm{H})$ of surface projection depends on the effective spark diameter (D) which is the sum of wire electrode diameter (d) and spark gap (SG). Larger the wire diameter wider will be the surface projection on WEDMed surface. For a fixed wire electrode of diameter (d), surface projection is only influenced by the spark gap which is the 
function of discharge energy across the electrodes. Discharge energy in WEDM is function of discharge current (Ip) and pulse duration (Ton) (Boujelbene et al., 2009). In this study, the influence of three important WEDM parameters namely discharge current (Ip), pulse-on time (Ton) and pulse-off time (Toff), have been examined on length $(\mathrm{H})$ of surface projections.

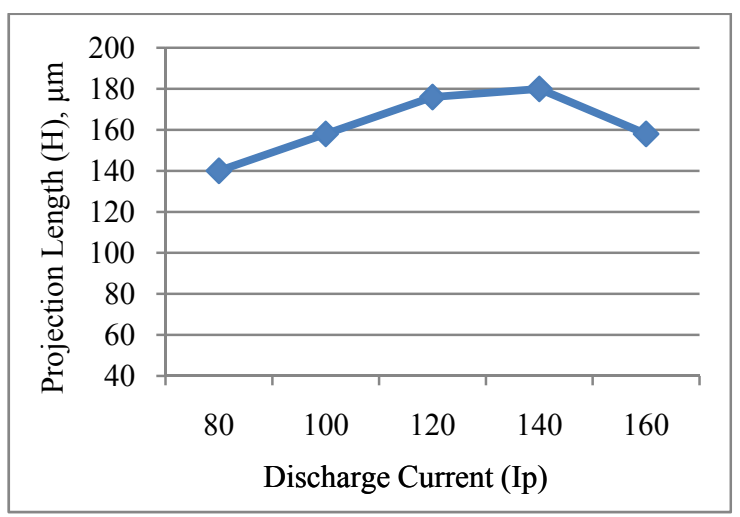

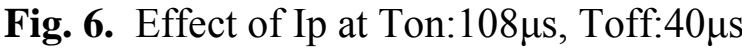

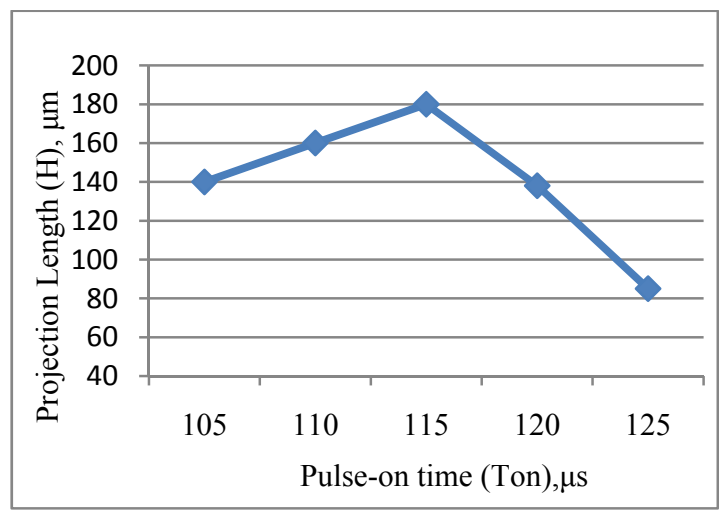

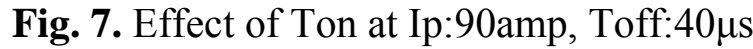

Fig. 6 and Fig. 7 show the effect of discharge current (Ip) and pulse-on time (Ton) on projection length (H) respectively, at pulse-off time (Toff) $40 \mu \mathrm{s}$; servo voltage $30 \mathrm{~V}$; dielectric flow rate $10 \mathrm{LM}^{-1}$; wire tension $10 \mathrm{~N}$; wire feed rate $8 \mathrm{~m} / \mathrm{min}$. Increase in discharge current (Ip) and pulse duration (Ton) increases the discharge energy across the wire electrode and work material which results in large ionization in spark gap and hence large effective spark diameter. As a result, unmachined area increases with increase in Ip and Ton up to some limiting value. But further increase in discharge energy may cause more melting of surface material and hence more eroded debris coagulate in spark gap which deteriorates the shape of the projection as shown in Fig. 8 to Fig. 10.

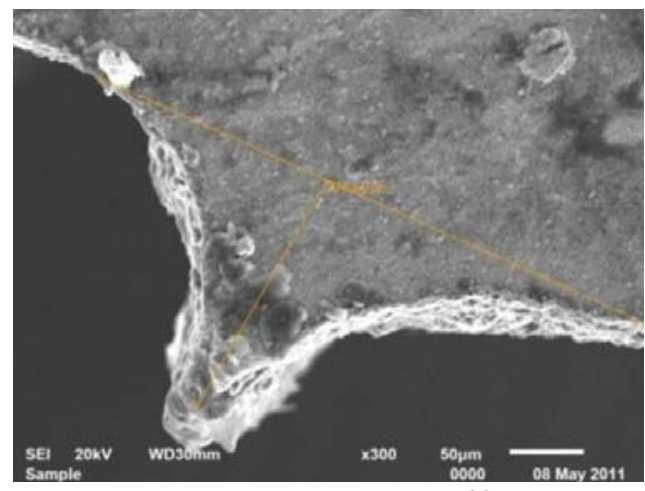

Fig.8. Ip:120amp, Ton:108 $\mu$ s, Toff: $40 \mu \mathrm{s}$

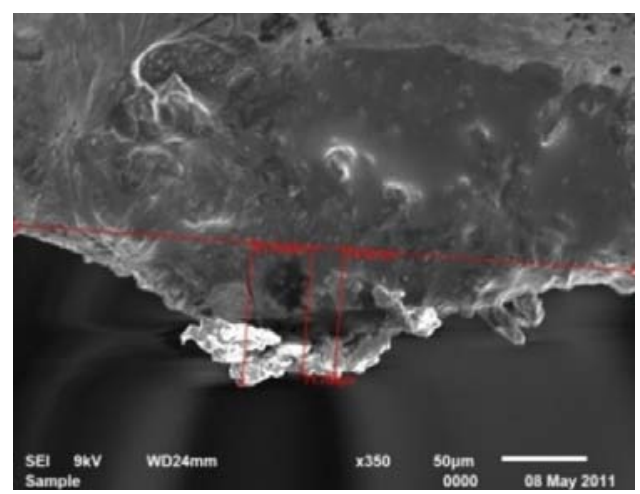

Fig. 10. Ip:140amp, Ton:122mu, Toff:40mu

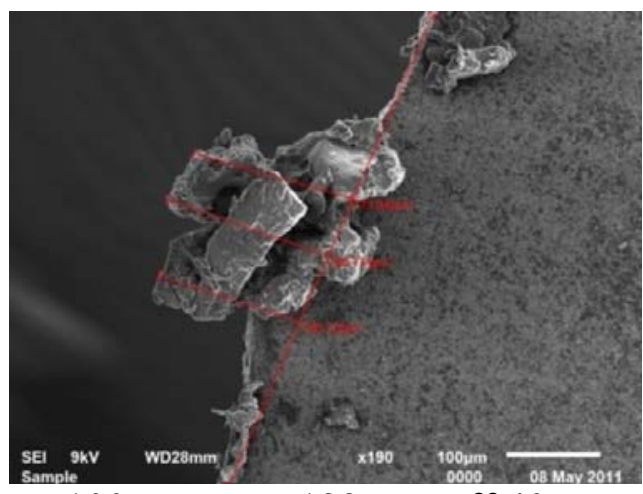

Fig. 9. Ip:100amp, Ton: $122 \mu \mathrm{s}$, Toff: $40 \mu \mathrm{s}$

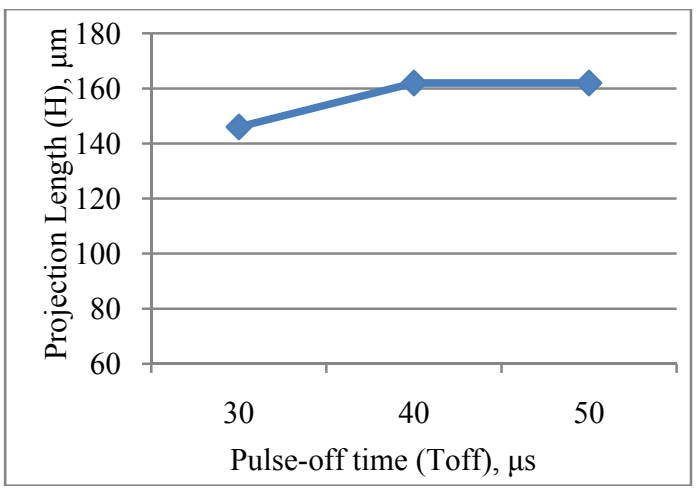

Fig. 11. Effect of Toff at Ip:90amp, Ton:110 
The melting and evaporation temperature are $2800^{\circ} \mathrm{C}, 6000^{\circ} \mathrm{C}$ for $\mathrm{WC}$ and $1320^{\circ} \mathrm{C}, 2700^{\circ} \mathrm{C}$ for $\mathrm{Co}$, respectively (Saha et al., 2008). Therefore, discharge energy tends to melt, evaporate and remove cobalt even before the melting of WC. As a result the WC grains may be released without melting and hence coagulate in the spark gap. With short pulse off time, the removal time for disintegrated particles from the gap being insufficient which result into arcs between electrodes. Increasing Toff results into easy escape of the carbide debris which results in little increase in projection length as shown in Fig. 11.

\subsection{Removal of surface projections}

Removals of unwanted surface projections are compulsory to improve the die performance and quality of finish components. Using grinding and milling operation, these surface projections can be eliminated form large size cavities having flat surfaces. But in case of small cavities having complex geometries and tapers, trim cutting operation on WEDM is best alternative. In trim cutting operation on WEDM, wire electrode traces back the same path with certain wire offset value and low discharge energy with respect to first or rough cut (Sarkar et al., 2008). In present work, maximum three number of trim cuts were performed with different wire offset values and constant parameters of Ip: 90amp.; Ton: $105 \mu \mathrm{s}$; Toff: $30 \mu \mathrm{s}$; SV: 30V; WF: 2m/min.; DFR: 4LM ${ }^{-1}$. Fig. 12 shows the effect of number of trim cuts on surface projections with wire offset (WO) values of $130 \mu \mathrm{m}$ and $136 \mu \mathrm{m}$.

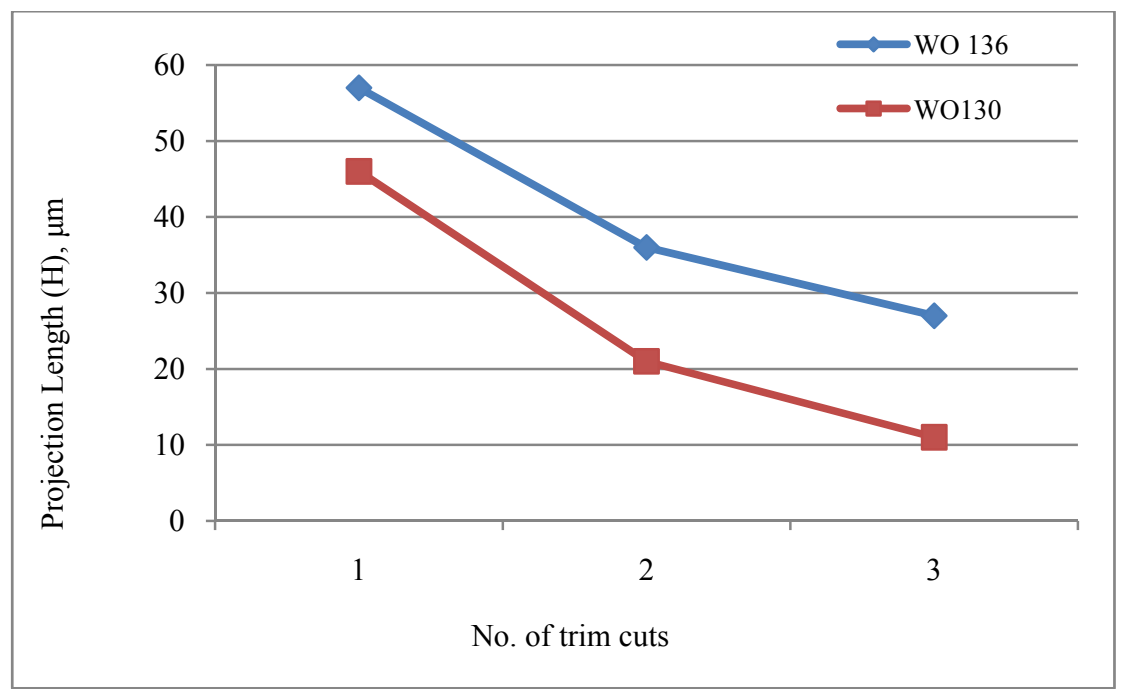

Fig. 12. Effect of trim cuts on surface projections

Fig. 12 shows the noticeable effect of wire offset and trim cut number, in minimizing the surface projections. After three trim cuts with wire offset $130 \mu \mathrm{m}$, surface projection minimizes up to $11 \mu \mathrm{m}$ which further can be reduced by increasing the number of trim cuts.

\section{Conclusions}

In present study, unmachined surface area named as surface projection has been observed on die surface after first or rough cut in WEDM process. These surface projections are function of wire electrode diameter and discharge energy across the electrodes. Increasing discharge energy results in increase in unmachined surface area on work surface. Also high discharge energy with low pulse-off time results in deep heat affected zone and deteriorated surface projections with more re-deposited eroded work material around the region F and I (Fig. 2).

In order to eliminate these surface projections after rough cut from small and complex intricate geometries, trim cutting operation on WEDM is best option. In trim cut, discharge energy and wire offset value plays a significant role in minimizing the surface projections. In present study, using wire 


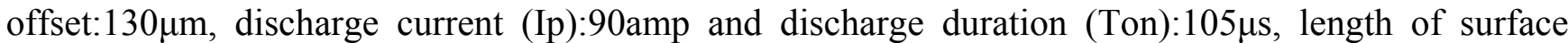
projection minimizes below $50 \mu \mathrm{m}$ and $11 \mu \mathrm{m}$ after one and three trim cuts respectively. Therefore, using low discharge energy and appropriate wire offset value, surface projections can be minimized successfully using two or more trim cuts.

This new finding would attract more researchers for deep study in intricate machining on WEDM for improving the quality of machined surfaces.

\section{References}

Boujelbene, M., Bayraktar, E., Tebni, W., Salem, \& Ben, S. (2009). Influence of machining parameters on the surface integrity in electrical discharge machining. Archives of Materials Science and Engineering, 37 (2), 110-116.

Ho, K.H., Newman, S.T., Rahimifard, S., \& Allen, R.D. (2004). State of art in wire electrical discharge machining (WEDM). International Journal of Machine Tools and Manufacture, 44, 1247-1259.

Juhr, H., Schulze, H.P., Wollenberg, G., \& Kunanz, K. (2004). Improved cemented carbide properties after wire EDM by pulse shaping. Journal of Material Processing Technology, 149, 178-183.

Jangra, K., Jain, A., \& Grover, S. (2010). Optimization of multiple-machining characteristics in wire electrical discharge machining of punching die using grey relational analysis. Journal of Scientific and Industrial Research, 69, 606-612.

Kruth, J.P., \& Stevens, L. (1995). Study of the white layer of a surface machined by die sinking electrical discharge machining. Annals of the CIRP, 44(1), 169-172.

Kahng, C.H., \& Rajurkar, K.P. (1997). Surface characteristics behaviour due to rough and finish cutting by EDM. Annals of the CIRP, 25(1), 77-82.

Lee, S.H., \& Li, X.P. (2003). Study of the surface integrity of the machined workpiece in the EDM of tungsten carbide. Journal of Material Processing Technology, 139, 315-321.

Puri, A.B., \& Bhattacharyya, B. (2005). Modelling and analysis of white layer depth in a wire-cut EDM process through response surface methodology. International Journal of Advance Manufacturing Technology, 25, 301-307.

Rebelo, J.C., Marao, Dias, A., Kremer, D., \& Lebrun, J.L. (1998). Influence of EDM pulse energy on the surface integrity of martensitic steels. Journal of Material Processing Technology, 84, 90-96.

Saha, P., Singha, A., \& Pal, S.K. (2008). Soft computing models based prediction of cutting speed and surface roughness in wire electro-discharge machining of tungsten carbide cobalt composite. International Journal of Advance Manufacturing Technology, 39, 74-84.

Sarkar, S., Sekh, M., Mitra, S., \& Bhattacharyya, B. (2008). Modelling and optimization of wire electrical discharge machining of $\gamma$-TiAl in trim cutting operation. Journal of Material Processing Technology, 205, 376-387.

Veldhuis S.C., Dosbeva, G.K., \& Elfizy, A. et al. (2010). Investigation of white layer formation during machining of powder metallurgical Ni-based ME 16 Superalloy. Journal of Material Engineering and Performance, 19(7), 1031-1036.

Wang, C.C., Chow, H. M., Yang, L. D., et al. (2009). Recast layer removal after electrical discharge machining via Taguchi analysis: a feasibility study. Journal of Material Processing Technology, 209, 4134-4140. 